\title{
Gilberto Freyre e a educação: raça, democracia e ensino de história e cultura afro-brasileiras
}

\author{
Amurabi Oliveira \\ Universidade Federal de Santa Catarina
}

\section{Resumo}

0 advento da Lei n. ${ }^{0}$ 10.639/03 tem nos levado a uma série de problematizações em torno de nossa cultura e identidade, revisitando um questionamento que foi corriqueiro no pensamento social brasileiro nos anos de 1920-30: quem nós somos? Para nos auxiliar na tentativa de responder a esta pergunta, proponho neste artigo a realização de uma reflexão em torno das contribuições da obra de Gilberto Freyre (1900-1987) para esta questão, o que será desenvolvido a partir de dois eixos: no primeiro, buscarei explanar a relação entre raça e educação no pensamento do autor; no segundo, o foco recairá sobre a interpretação de Freyre em torno da cultura africana na constituição da sociedade brasileira, e neste ponto farei um esforço em indicar como tal interpretação pode contribuir para a discussão que vem sendo trazida por meio da Lei n. ${ }^{0}$ 10.639/03.

Palavras-chave: Gilberto Freyre. Lei n. ${ }^{\circ}$ 10.639/03. Ensino de história e cultura afro-brasileira. Antropologia da educação. 


\section{Gilberto Freyre and education: race, democracy and teaching of african-brazilian history and culture}

The advent of Law No. 10,639/03 has led us to a series of problems concerning our culture and identity, revisiting a question that was commonplace in Brazilian social thought in 1920's and 30's: "Who are we?". To assist us in trying to answer this question, in this article I propose a reflection on the contributions of the work of Gilberto Freyre (1900-1987) towards this question, which will be developed based on two axes: In the first I will attempt to explain the relationship between race and education in the author's thought, in the second the focus will be Freyre's interpretation regarding African culture in the formation of Brazilian society, and at this point I will make an effort to indicate how such interpretation can contribute to the discussion brought about by lthe law No. 10,639/ 03.

Keywords: Gilberto Freyre. Law 10.639/03. Teaching of African-Brazilian History and Culture. Anthropology of Education.

\section{Gilberto Freyre y educación: raza, democracia y la enseñanza de historia y cultura afro-brasileñas}

El advenimiento de la Ley $N^{\circ}$ 10.639/03 nos ha llevado a una problematización con respecto a nuestra cultura e identidad, volviendo a visitar un cuestionamiento que era un lugar común en el pensamiento social de Brasil en los años 1920/30: ¿qué somos nosotros? Para ayudarnos a tratar de responder a esta pregunta en este artículo me propongo llevar a cabo una reflexión sobre la contribución de la obra de Gilberto Freyre (1900-1987) para este problema que se desarrollará a partir de dos ejes: al principio yo busco explicar la relación entre raza y educación en el pensamiento del autor, en el segundo la atención se centrará en la interpretación de Freyre alrededor de la cultura africana en la formación de la sociedad brasileña en este punto voy a hacer un esfuerzo para indicar como dicha interpretación puede contribuir a la discusión que se ha señalado en la mencionada Ley.

Palabras-clave: Gilberto Freyre. Ley 10.639/03. Enseñanza de la historia y la cultura afro-brasileña. Antropología de la educación. 


\section{Introdução}

$O$ pernambucano Gilberto Freyre (1900-1987) teve toda sua trajetória intelectual marcada por polêmicas, não à toa sua obra tem sido alvo de constantes revisões sempre controversas (Amado et ali, 1962; Souza, 2000; Andrade, 2002; PallaresBurke, 2005; Bastos, 2006; Larreta, Giucci, 2007; Lehmann, 2008; Motta, Fernandes; 2013), como não poderia ser diferente dada a idiossincrasia constitutiva de seu trabalho, que passeava livremente pelos campos da sociologia, antropologia, história, literatura e geografia, sem contar as inúmeras referências ao direito, à biologia, à demografia etc.

A apreensão de seu pensamento torna-se desafiadora tendo em vista o caráter eclético que sua obra assume, não se prendendo aos limites disciplinares, o que, longe de indicar um desconhecimento dos padrões modernos de produção do conhecimento, aponta para uma posição contrária a estes. Como nos indica Cardoso (2013), Freyre não era adepto do que denominou de cientificismo, ou seja de uma visão positivista da ciência; contudo, isso não indica que devamos nos eximir de alguns questionamentos em torno do caminho por ele escolhido: “[...] seus conceitos básicos captaram o fundamental do processo histórico? Sua abordagem culturalista foi precisa ou extrapolou englobando o conjunto do país ao que vivenciara e analisara numa região? Justificou suas generalizações, embora não estatisticamente?". (Cardoso, 2013, p. 101)

Ainda assim parece-me instigante pensar a atualidade desse autor e suas possíveis contribuições para um campo no qual ele tem sido pouco explorado: a educação. Sua passagem como professor da Escola Normal de Pernambuco, no final dos anos de 1920, ainda é pouco conhecida e parcamente explorada entre seus estudiosos, à exceção do trabalho de Meucci (2006), assim como sua participação efetiva à frente do Centro Regional de Pesquisas Educacionais em Recife durante os anos de 1950'. Alguns de seus trabalhos que se dirigem diretamente às questões educacionais como “Em torno da situação do professor no Brasil" (1953) e "Palavras às professoras rurais do Nordeste" (1956) continuam solenemente ignorados tanto por cientistas sociais quanto por educadores.

De forma mais específica, busco neste artigo refletir em torno das possibilidades de contribuição da obra de Gilberto Freyre para o ensino de história e cultura afrobrasileira, obrigatório em toda a educação básica no Brasil por meio da Lei n. ${ }^{0}$ $10.639 / 03$, ainda que reconheça aqui que se trata da transposição de argumentos teóricos elaborados principalmente na primeira metade do século XX para uma discussão intelectual e política que se substancia no começo do século XXI.

1. Para uma melhor análise vide Meucci (2012). 
Porém, enquanto clássico do pensamento social brasileiro, acredito que Freyre possui questões interessantes que devem ser discutidas no campo educacional. Certamente, dentre todas as possibilidades existentes para realizar uma interface entre a obra de Freyre e o campo educacional, esta escolhida é uma das mais delicadas, considerando a atribuição que é dada ao autor como defensor do "mito da democracia racial", com relação ao qual a Lei n. ${ }^{0}$ 10.639/03 vai na contramão, buscando miná-lo.

Tendo em vista tais questões, o texto possuirá dois eixos norteadores: no primeiro, buscarei explanar a relação entre raça e educação no pensamento do autor; no segundo, o foco recairá sobre a interpretação de Freyre em torno da cultura africana na constituição da sociedade brasileira, e neste ponto farei um esforço em indicar como tal interpretação pode contribuir para a discussão que vem sendo trazida por meio da Lei n. ${ }^{0}$ 10.639/03.

\section{Raça, Educação e Democracia no Pensamento de Freyre}

Para uma compreensão mais precisa da obra de Freyre, é importante ressaltar as influências fundamentais que lastreiam seu pensamento, o que remete, inevitavelmente, à sua experiência acadêmica nos Estados Unidos, especialmente durante o mestrado na Universidade de Columbia, durante o qual teve contato com Franz Boas (1858-1942), a quem atribuiu decisiva influência na formulação de suas ideias, principalmente no que tangencia à distinção entre raça e cultura. Entretanto, Consorte (1997) problematiza a leitura do culturalismo realizada por Freyre, uma vez que teria confluído para uma perspectiva integracionista, que se mostrou bastante problemática no campo educacional. Em outra direção, Motta (2008) questiona a herança intelectual direta de Boas sobre Freyre, indicando um pensador que poderia tê-lo influenciado de forma mais decisiva: Charles Maurras (1868-1952).

Outro aspecto relevante diz respeito ao fato de que essa experiência acadêmica - levou à formulação de um exercício contínuo e comparativo entre esse país, especialmente a região Sul, e o Brasil; não à toa, em muitas passagens de livros sobre os Estados Unidos por ele lidos, havia a anotação ao lado: "Brasil" (PallaresBurke, Burke, 2009). Esta questão mostra-se essencial para compreender o que o autor quis dizer por democracia racial; expressão que, em verdade, é utilizada poucas vezes ao longo de sua vasta produção intelectual e possui valor apenas em termos relativos, tendo em vista que o Brasil de Freyre não chega a ser plenamente uma democracia étnico-racial, porém, caminharia para tanto mais que outras nações, como os Estados Unidos (Freyre, 1968). Como nos indica o autor: 
[...] três raças e três culturas se fundem em condições que, de modo geral, são socialmente democráticas, ainda que até agora permitindo apenas um tipo ainda imperfeito de democracia social; imperfeito tanto na sua forma econômica como nas suas formas políticas de expressão. Mas com todas as suas imperfeições, de base econômica e de formas políticas de convivência democrática, o Brasil impõe-se hoje como uma comunidade cuja experiência social pode servir de exemplo ou estímulo a outras comunidade modernas. (Freyre, 2001b, p. 198, grifo nosso)

Além do reconhecimento dos limites de tal democracia, é importante ressaltar que todo o pensamento de Freyre é repleto de elementos contrastantes que parecem, à primeira vista, contraditórios, pois, ao indicar que houve no Brasil uma escravidão mais branda que aquela que ocorrera nos Estados Unidos ou ainda na América Espanhola, também aponta para o caráter sádico dos senhores e senhoras de escravos e relata em detalhes as crueldades ocorridas no período colonial (Freyre, 2005), o que se torna possível por meio do que o autor denomina de equilíbrio de antagonismos, que seria uma das marcas principais da cultura brasileira.

Faz-se necessário ainda situar o debate acadêmico de seu tempo, especialmente aquele existente na época da publicação de "Casa Grande \& Senzala”, em 1933. Como bem nos elucida Bastos (2006), uma das marcas fortes do ensaísmo dos anos de 1920 foi a discussão em torno da raça, que era, nesse momento, componente fundamental da questão nacional. Nesse período, popularizamse, nos ciclos intelectuais brasileiros, teorias defensoras de uma perspectiva arianista, que apontavam o embranquecimento da população como único caminho para a viabilidade deste país como Nação, o que irá se articular com um forte discurso assumido como científico (Schwarcz, 1993). A publicação de "Casa Grande \& Senzala" vai de encontro a essas teorias, ao apontar não apenas a dimensão constitutiva do negro e do índio na sociedade brasileira, como também que, mesmo nossa herança europeia (portuguesa), era em grande medida africana, dado o processo de ocupação moura vivenciado na península Ibérica e a situação particular dos portugueses de viverem entre dois mundos, considerando inclusive sua posição geográfica. Ainda segundo Bastos:

Gilberto Freyre, ao colocar sob outra luz a questão, permite o equacionamento do problema em outro patamar. A raça vista como um "problema", um obstáculo à integração, perde sua força. A redefinição do problema passará pela discussão do regionalismo e ao papel desempenhado pelo patriarcado na gênese e consolidação da sociedade brasileira. (Bastos, 2006, p. 76) 
Pode-se afirmar, portanto, que Freyre inverte o sinal com o qual a questão da raça vinha sendo pensada até então. Mais que isso, trazia também uma complexificação do processo de colonização, ao apontar para a construção do mundo luso-tropical não apenas como uma imposição unívoca do colonizador europeu, dado que, para a adaptação do português nos trópicos, fez-se necessária uma incorporação de vários elementos presentes no indío e no negro, além de toda sua herança oriental.

As ideias expressas em Casa-Grande \& Senzala se situavam na direção oposta de grandes pensadores do período, com destaque para Oliveira Viana (1883-1951), que silenciou sobre o referido livro, como observou o próprio Freyre (1968). A formulação das hipóteses ali expostas estavam em consonancia com o exercício intelectual assumido por vários pensadores naquele período, que tentavam interpretar o Brasil e viam claramente o peso do passado sobre o presente como um elemento central para a elaboração dessa interpretação, ainda que pudessem divergir na forma de compreender o passado, bem como o peso que ele teria sobre o presente e futuro do país. Frisa-se que as ideias de Freyre foram revolucionárias naquele momento, solapando as teorias arianistas que predominavam na discussão sobre relações raciais no Brasil; entretanto não podemos olvidar que, décadas mais tarde, estas mesmas ideias passam a assumir um caráter profundamente conservador, uma vez que dirimiam a dimensão do conflito e eclipsavam o próprio racismo, em que pese a interpretação que passou a se difundir sobre a obra do autor pernambucano².

Interessante destacar que a questão educacional não foge em nenhum momento do olhar de Freyre, e, quando se refere à dimensão racial, esse tópico volta a ganhar destaque, pois, ao que parece, a educação pode ser entendida como um importante elemento que nos levaria rumo a uma "democracia social". Ao analisar o papel dos Jesuítas, ele realiza os seguintes apontamentos:

[...] concentraram-se os jesuítas em desenvolver um sistema de educação que trouxesse sob a sua influência os filhos dos colonos ricos e também as crianças indígenas. E o fato é que nas suas escolas, escolas que logo se fizeram famosas, o latim e a retórica que nelas se ensinavam tanto eram obrigatórios para os filhos de branco como para os filhos de índio.

Negros e mulatos não eram, entretanto, geralmente aceitos nessas escolas, razão por que não se deve contar o jesuíta entre as influências que favoreceram, no Brasil, o amalgamento das raças e a democratização social e étnica da Colônia. (Freyre, 2001b, p. 101-1111

2. Para uma melhor análise do pensamento do Freyre frente aos intelectuais de seu tempo, vide os trabalhos de Bastos (2006), Llarreta e Giucci (2007), Pallares-Buke e Burke (2009), Motta e Fernandes (2013). 
Há, portanto, uma compreensão por parte de Freyre de que uma alteração nas relações raciais rumo a uma suposta "democracia" perpassa, necessariamente, a questão educacional. Isso pode ser encontrado de forma ainda mais explícita em "Sobrados \& Mucambos", publicado originalmente em 1936, especialmente no capítulo “A Ascensão do Bacharel e do Mulato”, que indica a possibilidade de ascensão da figura do bacharel na passagem do Brasil rural para o Brasil mais urbano, referindo-se não apenas ao bacharel rico que vai estudar na Europa, como também ao bacharel pobre que "[...] estudara ou se formara, às vezes, graças ao esforço heroico da mãe quitandeira ou do pai funileiro." (Freyre, 2006, p. 722). Torna-se evidente como, na obra de Freyre, a educação impacta diretamente as relações raciais, não à toa os mulatos que se fizeram bacharéis podiam gozar dos "benefícios" de serem tidos como brancos em uma sociedade escravocrata. Não sem menor relevância, o advento da República mostrar-se-ia fundamental nesse processo de consolidação que vinha, desde o Império, articulado com o angariamento de títulos escolares.

[...] desde o Império os títulos acadêmicos foram no Brasil meios de ascensão social que favoreceram particularmente os moços mestiços ou de origem modesta. Eram cartas de branquitude sociológica que os foram tornando iguais aos brancos de origem fidalga: às vezes seus superiores pelo talento e pelo saber aplicado à política, à advocacia, à medicina, ao sacerdócio, à engenharia: a atividades socialmente prestigiosas.

Esse processo de valorização do homem de origem modesta ou de condição étnica socialmente inferior, pelo título acadêmico, acentuou-se com o advento da República; e não apenas através das referidas academias ou escolas superiores, como através das academias ou escolas militares. Não tanto a da Marinha como a do Exército. Embora continuando, neste ponto, a obra do Império, e não propriamente inovando na matéria, a República avivou no Brasil as oportunidades de ascensão social, particularmente política, dos mestiços e dos plebeus. (Freyre, 2004, p. 536)

Nesse aspecto, a profissão de professor ocupará uma posição de destaque nesta íntima relação entre educação e relações raciais, no texto “Em torno da situação do professor no Brasil", publicado originalmente em inglês no Year Book of Education da Universidade de Londres em 1953. Freyre realiza o seguinte apontamento:

Ao final do século XVIII e durante a primeira metade do século XIX, uma carreira, uma profissão acadêmica, no Brasil, representava um dos meios pelos quais o jovem mestiço ou filho de modesta família urbana branca ou recém-chegada da Europa 
podia elevar-se socialmente de maneira a competir com os filhos da aristocracia rural em atividades não só intelectuais como políticas. Como bachareis, advogados, doutores em medicina, jovens de origem menos aristocrática e até plebeia tiveram então a oportunidade de formar uma nova aristocracia: uma aristocracia de beca coroada por outra de borla e capelo. E, nessa nova aristocracia, era natural que os professores das Faculdades de Direito e de Medicina se tornassem importantíssimos príncipes acadêmicos: eles não somente eram formados em escolas superiores mas professores ou mestres das mesmas escolas. (Freyre, 2003, p. 88)

Sendo assim, ao reconhecer a ascensão social dos mulatos, ou mestiços, há uma afirmativa implícita em torno da existência de uma sociedade estratificada a partir de critérios raciais, mas que era sensivelmente impactada pelas mudanças educacionais em curso. Nesse mesmo texto, ele se refere ainda ao processo paulatino de ampliação do número de escolas, que implicou não apenas um crescente contingente de mulatos que tiveram acesso à educação e, por consequencia, às possibilidades de ascensão social, como também uma perda de prestígio da profissão de professor, especialmente o primário.

Também as escolas militares ocuparam um importante lugar enquanto promotoras de oportunidades educacionais para os mestiços, tendo ocorrido:

[...] facilidade para os brasileiros de origem modesta e de condição étnica, em certos meios, por inferior, de se instruírem em escolas militares e a expensas do Estado; e se instruírem nessas escolas não apenas em assuntos tecnicamente militares como nos políticos, sociológicos, econômicos, tornando-se de certo modo rivais dos bachareis em direito, dos médicos, dos engenheiros, dos sacerdotes, em aptidões para o exercício de cargos públicos. (Freyre, 2004, p. 548)

Em “Vida Social no Brasil nos Meados do Século XIX”, que foi sua dissertação de mestrado publicada em 1922 no periódico Hispanic American Historical Rewiew, volume 5, Freyre realiza o seguinte apontamento sobre a questão educacional:

O liberalismo do Império, tão pronto em reconhecer o mérito individual, era favorável aos recém-vindos. Favorável a quantos indivíduos de origem modesta - até filhos de escravos - se valorizassem pela instrução superior ou pelo casamento de moça de família ilustre. (Freyre, 2008b, p. 65)

Observa-se, portanto, que, na passagem do século XIX para o XX, a educação continua, na análise do autor, a ser um relevante meio para a ascensão 
social e alteração da estratificação posta no Brasil rumo à consolidação de uma democracia étnica; ainda que caiba aqui ressaltar mais uma vez que as questões levantadas por Freyre possuem sempre um valor relativo, pois o Império, assim como a República, encontrava-se mais aberto que a Colônia para o reconhecimento do "mérito individual", mas isso não quer dizer que as desigualdades tivessem desaparecido, muito menos em termos étnicos.

Como bem esclarece Souza (2000), para Freyre, o advento de uma sociedade mais urbana abre possibilidades de mobilidade social ainda até então imprevistas, operacionalizadas tanto pelo ingresso dos mulatos e mestiços na chamada "cultura superior", transformando-se tanto pelo bacharel, quanto pela figura do "mulato habilidoso", que assume atividades manuais que demandam mais conhecimento e perícia. Ainda segundo Souza, o processo de modernização da sociedade brasileira se deu "de fora para dentro", "de baixo para cima" e de "cima para baixo". Para Freyre, conforme entrevista concedida a Lêda Rivas em 15 de março de 1980³ , devemos ter em vista a visceral relação entre os problema de classe, raciais, culturais e educacionais, levantando o seguinte questionamento:

Porque depois que o Brasil fez o seu festivo e retórico 13 de maio, quem cuidou da educação do negro? Quem cuidou de integrar esse negro liberto à sociedade brasileira? A Igreja? Era inteiramente ausente. A República? Nada. A nova expressão de poder econômico do Brasil que sucedia ao poder patriarcal agrário e que era a urbana industrial? De modo algum.

Desse modo, segundo Freyre, para compreender o racismo no Brasil, hão de se considerar os múltilplos fatores envolvidos na questão, com um especial destaque para o educacional. Interessa-nos aqui reafirmar que, no pensamento de Freyre, estávamos situados em uma sociedade desigual em termos raciais, pois, como ele enfaticamente ressalta, "Não que inexista preconceito de cor ou de raça juntamente com preconceitos contra a mistura de classes no Brasil. Existe." (Freyre, 2011, p. 36), e ainda "Tem existido e ainda existe no Brasil distância social entre os diferentes grupos da população." (Ibidem, p. 150). Neste sentido, é válido ressaltar que Freyre pretendeu explicar as relações raciais no Brasil principalmente por causas ideológicas, abrangendo fatores muitas vezes sutis, como ethos cultural e atitudes religiosas (Motta, 2000), e, desse modo, captar como tais relações são pensadas na obra do autor requer atenção do leitor.

3. Disponível em: http://bvgf.fgf.org.br/portugues/vida/entrevistas/anarquista.html. Acesso em: 30 de maio de 2014. 


\section{Possíveis Contribuições para o Ensino de História e Cultura Afro- Brasileira}

A introdução da história e cultura afro-brasileira nos currículos escolares da educação básica brasileira insere-se no lastro de dois fenômenos que ocorrem de forma concomitante no Brasil: por um lado, há a emergência dos chamados novos movimentos sociais, que colocam em pauta reivindicações referentes à identidade étnico-racial, religiosa, de gênero etc. (Gohn, 2010), neste caso específico há uma politização do conceito de raça por meio do Movimento Social Negro, compreendida enquanto uma construção social (Gomes, 2012); por outro, há a entrada cada vez mais forte no Brasil, fomentada principalmente por organismos internacionais, da questão da diversidade, em suas múltiplas significações, nas políticas públicas, especialmente as educacionais. (Rodrigues, Abramowicz, 2013)

Para se chegar até a promulgação da Lei n. ${ }^{0} 10.639 / 03$, foi percorrido um longo trajeto, e, apesar de todo o embate em torno do conceito de "democracia racial”, tal como é atribuído certa ou erradamente a Freyre, é inegável que um dos marcos para essa discussão no espaço público foi a promoção do Primeiro Congresso Afro-Brasileiro organizado por Freyre em Recife, em 1934, no qual:

[...] o negro foi considerado predominantemente um novo objeto de conhecimento, que devia ser incorporado à agenda social, tanto na teoria quanto na prática. As denúncias relativas à discriminação, ao conflito de identidade e ao conflito racial mesclaram-se com a discussão científica sobre sua condição social. (Larreta, Giucci, 2007, p.526)

Tal evento teve como uma de suas marcas a inovação na forma de abordar essa temática. Psiquiatras, historiadores, sociólogos, antropólogos, alunos de liceus, babalorixás, ex-escravos, negros analfabetos etc. compunham o corpo dos palestrantes do evento, formando uma reunião de interesses e perspectivas distintas no estudo sobre o negro, que constituíram uma transformação radical na abordagem do tema no Brasil, destacando-se a reflexão em torno do seu papel na constituição da Nação.

Nunca é demais rememorar o embate desse autor com os defensores do arianismo no seu tempo e como sua obra erigiu-se em torno da afirmativa de que o Brasil, tal como ele existia, era fruto da herança africana, tanto de forma direta, quanto indireta, ao reconhecer a influência moura na constituição do povo português. Eram, portanto, os antecedentes da colonização brasileira não apenas europeus como também asiáticos e africanos. (Freyre, 2011)

Por meio de uma multiplicidade de fontes, pouco usuais para o período, 
Freyre tenta reconstituir a formação do povo brasileiro, ainda que os críticos possam apontar para os limites de sua análise, que em última instância teria generalizado o Nordeste para o Brasil, ou mais ainda Pernambuco (PallaresBurke, Burke, 2009). 0 que se torna evidente é que não houve a transposição de uma cultura europeia para os trópicos, mas sim a constituição de uma nova, que ele chamará de luso-tropical, na qual o europeu parece, por vezes, um elemento secundário em relação ao africano. Em uma das passagens mais conhecidas de "Casa Grande \& Senzala", o autor nos elucida que:

Todo brasileiro, mesmo o alvo, de cabelo louro, traz na alma, quando não na alma e no corpo - há muita gente de jenipapo ou mancha mongólica pelo Brasil -, a sombra, ou pelo menos a pinta, do indígena ou do negro. No litoral, do Maranhão ao Rio Grande do Sul, e em Minas Gerais, principalmente do negro. A influência direta, ou vaga e remota, do africano.

Na ternura, na mímica excessiva, no catolicismo em que se deliciam nossos sentidos, na música, no andar, na fala, no canto de ninar menino pequeno, em tudo que é expressão sincera de vida, trazemos quase todos a marca da influência negra. Da escrava ou sinhama que nos embalou. Que nos deu de mamar. Que nos deu de comer, ela própria amolengando na mão o bolão de comida. Da negra velha que nos contou as primeiras histórias de bicho e de mal-assombrado. Da mulata que nos tirou o primeiro bicho-de-pé de uma coceira tão boa. Da que nos iniciou no amor físico e nos transmitiu, ao ranger da cama-de-vento, a primeira sensação completa de homem. Do moleque que foi o nosso primeiro companheiro de brinquedo. (Freyre, 2005, p. 367)

Esse trecho sintetiza, de modo bastante claro, a forma como Freyre via a presença africana na cultura brasileira; para ele não haveria como pensar 0 Brasil desvinculado de uma reflexão em torno do lugar do africano na constituição do ethos brasileiro. Como já afirmei anteriormente, a questão se reforça ao adentrarmos na interpretação do autor de que nossa herança cultural europeia é, em si mesma, também africana, pois os portugueses seriam, por excelência, um povo dividido entre dois mundos, mais que isso:

Dos povos europeus que se lançaram à colonização da América nenhum menos dominado pelo complexo de superioridade ou de pureza de raça do que o português, uma nação quase não europeia. A sua mística de unidade ou de pureza foi de religião ou de status religioso - a religião católico-romana ou o status cristão - e não de raça. (Freyre, 2011, p. 199, grifo nosso) 
Esses aspectos estavam postos de forma mais evidente principalmente na sociedade patriarcal, sendo algo verificável por meio de vários hábitos culturais oriundos dos mouros, como o costume das mulheres de taparem os rostos, o gosto pelo azulejo, o cafuné etc. Porém, a passagem para o século XIX, principalmente com a vinda dos ingleses, teria demarcado um processo de "reuropeização" da sociedade brasileira, o que será visto de forma bastante negativa por Gilberto Freyre, dada sua compreensão sobre a relevância da presença de tais elementos na constituição do Brasil enquanto Nação. (Freyre, 2008a)

Se o Parecer CNE/CP n. ${ }^{\circ}$ 003/2004 deixa bastante clara a necessidade de não apenas se mudar o foco de como se interpreta o lugar dos africanos e sua cultura na formação da sociedade brasileira, bem como de ampliar os conhecimentos sobre o passado, o presente e as perspectivas de futuro de África, parece-me que realmente o conhecimento aprofundado da obra de Freyre é um elemento fundamental para esse processo.

Freyre é ainda um dos primeiros autores a complexificar o olhar sobre os africanos escravizados e trazidos para o Brasil, na medida em que aponta para a presença de africanos letrados (Freyre, 2001b, 2011), característica rara nesse momento mesmo entre a elite branca. Neste sentido, seu trabalho nos leva a repensar a África, indo para além de perspectivas estereotipadas sobre seu passado e presente. Porém, nunca é demais ressaltar que Freyre se propõe a pensar principalmente, mas não unicamente, o universo brasileiro; portanto, ele continuamente pensa em termos afro-brasileiros, dado que mesmo a presença africana também teria se abrasileirado.

0 que nos parece de mais interessante em relação com a presença de cultura negra - maometana ou árabe ou animista - no Brasil é que parte dela aqui se abrasileirou de tal modo, que dos libertos de regresso à África, durante a segunda metade do século XIX, quase todos ali se mantiveram como "brasileiros", vivendo vida à parte da dos negros africanos: inclusive - grande número deles - vida de católicos à maneira brasileira, alguns devotos de um Nosso Senhor do Bonfim que, na África, só fez mudar de sexo, tornando-se Nossa Senhora. (Freyre, 2004, p. 792)

Este tratamento nos ajuda a compreender também que a cultura age em múltiplos sentidos, sendo apressada qualquer leitura que a reduza a uma única direção, e que, portanto, pensar a cultura afro-brasileira demanda uma reflexão profunda sobre o Brasil. Parece-me clara a convergência entre a Lei n. ${ }^{0}$ 10.639/03 e o legado de Freyre, na medida em que:

Ao se resgatarem outros debates em torno da Lei n. ${ }^{0} 10.639$, tornam-se mais claras as mentalidades envenenadas que conformam resistência nas discussões com e 
entre educadores dentro das escolas. A Lei, ainda que tenha sido uma conquista da luta do segmento negro brasileiro, não está restrita a uma questão entre negros e brancos, mas diz respeito a um problema da sociedade brasileira. Qual sociedade se quer daqui 20,30, 40, 50 anos? Não é a sociedade do hoje, é a sociedade do amanhã que está em jogo. Não é uma sociedade para negros ou para brancos, mas para todos. É isso que está em pauta na lei em tela. Mesmo que ela peça urgência para a questão racial aqui e agora, não se pode confundir a questão maior, o amanhã da sociedade brasileira. A Lei n. ${ }^{0} 10.639$, nesse sentido, é mais que simplesmente ação afirmativa e não se confunde com a interpretação do sistema de cota, porque é mais que isso. Sua perspectiva é a de direitos humanos. (GUSMÃO, 2012, p. 104)

E, nesta mesma direção, Freyre preocupa-se com a formação nacional, com o lugar que os agentes sociais ocuparam nesse processo. Mais uma vez cabe aqui chamar a atenção para a sui generis análise do autor e o papel do equilíbrio de antagonismo, pois, se por diversas vezes ele não hesitou em indicar uma escravidão branda, ao menos em termos comparativos (Freyre, 2005), e mesmo que o Brasil constituísse a sociedade mais democrática das Américas (Freyre, 1973), também sem rodeios ele afirma incisivamente que foram instituídas aqui relações altamente sádicas entre os senhores e escravos, marcadas por uma crueldade notória. Quando entrevistado em 1935 e indagado se haveria no Brasil preconceito contra os negros e mulatos, o autor não hesita em afirmar que é "evidente", ainda que houvesse no Brasil uma "doçura" na relação entre brancos e negros que não se encontraria em outros países, mas que disso não poderia se concluir a ausência de preconceito de raça. (Larrete, Giucci, 2007)

A perspectiva eurocêntrica assumida pela escola brasileira, enquanto instituição social moderna, evidenciada pela Lei n. ${ }^{0} 10.639 / 03$, vincula-se diretamente ao processo denunciado por Freyre de valorização da cultura europeia em detrimento da africana enquanto elemento constitutivo do Brasil, que, segundo ele, teria tomado contornos mais evidentes durante o reinado de Dom Pedro II. Ainda segundo o autor:

[...] desprezar-se quanto fosse expressão grosseiramente africana do que se supunha incultura. Havia quem na corte desdenhasse da Bahia por ser terra de carurus e vatapás, comidas evitadas pelos próprios baianos mais esmerados em se comportarem como europeus finos; do mesmo modo que, na Província de Pernambuco, a gente mais requintada não tinha senão desdém pelos maracatus. (Freyre, 2004, p. 327-328)

Preocupa-se tal pensador em subverter a valorização cultural, positivando aquilo que historicamente fora menosprezado, o que o autor denominará de “[...] 
uma quase freudiana censura à influência do indígena ou do africano ou do mestiço na vida ou na cultura nacional." (Freyre, 2011, p. 170-171)

Sua contribuição ultrapassa ainda o aspecto meramente teórico, tendo em vista a singularidade metodológica por meio da qual ele constrói seu legado, recorrendo a fontes de pesquisa até então pouco usuais, indo para além do âmbito relativamente estreito de documentos usados pela maioria de seus predecessores (Burke, 1997), o que converge com o que é proposto pelas "Orientações e Ações para Educação das Relações Étnico-Raciais" (2006).

Em um dos seus mais inventivos trabalhos "Açúcar", publicado originalmente em 1939, o autor dedica uma pequena parte do livro, apenas a introdução, a uma análise da relação entre o açúcar e a construção da civilização nacional, chamando atenção tanto para os aspectos portugueses quanto africanos nesse cenário; o restante do livro se volta para receitas de doces, bolos e sorvetes. Sobre essa realidade Freyre tece as seguintes considerações:

Sem a escravidão não se explica o desenvolvimento, no Brasil, de uma arte de doce, de uma técnica de confeitaria de uma estética de mesa, de sobremesa e de tabuleiro tão cheia de complicações e até de sutilezas que exigindo tanto vagar, tanto lazer, tanta demora, tanto trabalho no preparo do enfeite e dos doces, dos bolos, dos pratos, das toalhas e das mesas. Só o grande lazer das sinhás ricas e o trabalho fácil das negras e das molecas explicam as exigências de certas receitas das antigas famílias das casas-grandes e dos sobrados; receitas quase impossíveis para os dias de hoje. (Freyre, 2007, p. 70)

Não se trata de reduzir a presença africana a uma contribuição pontual na cultura brasileira, mas, sim, de afirmar sua onipresença nesse cenário. Assim sendo, o professor pode se valer da multiplicidade de receitas que Freyre nos presenteia para pensar a cultura em movimento no espaço da sala de aula, trazendo uma atividade prática para a escola mediante a qual se possa pensar a cultura afro-brasileira; afinal, como bem elucida Levi-Strauss (2010), a cozinha é uma linguagem e cada sociedade codifica suas mensagens por meio de signos particulares dentro dela; sendo assim, creio que nenhum pensador antes de Gilberto Freyre nos fez perceber a culinária como algo tão significativo para compreender o Brasil.

Em sua fala para as professoras rurais, proferida em 15 de maio de 1956, na Escola de Especialização Murilo Braga, em Recife, Freyre ressalta a necessidade de haver um esforço conjunto por parte dos professores e de outros profissionais para a valorização no espaço da sala de aula dos conhecimentos tradicionais, existentes em outros espaços educativos, indicando que: 
Erra o agrônomo empenhado na introdução de técnicas científicas num meio rural delas necessitado que não buscar a cooperação psicológica e social do padre, da professora, do boticário, dos velhos, das mulheres, e até do trovador ou cantador popular que houver na região. Nada de tecnicismo hirto e fechado: como o agrônomo ou o veterinário em meio rural, ou professor ou a professora deve ser um líder de reconstrução social; e não apenas um técnico. (Freyre, 1957, p. 10)

Essa ampliação dos diálogos para a construção da prática pedagógica, assim como a compreensão do professor como um agente social que vai para além do papel de reprodutor de um dado conhecimento, faz com que encontremos mais pontos de contatos entre Gilberto Freyre e as questões que vêm sendo pautadas a partir da Lei n. ${ }^{0}$ 10.639/03.

Outros tantos aspectos que não cabe aqui explanar, considerando os limites do trabalho, chamam a atenção na obra de Gilberto Freyre, pois ele indica a presença africana também na língua, na religião, nos modos corporais, enfim no ethos brasileiro como um todo.

Ainda que busque aqui ressaltar em que pontos Freyre pode contribuir para o debate em torno do ensino de história e cultura afro-brasileira, não quero dizer com isso que me furte de reconhecer os limites de seu trabalho; e, certamente, um dos pontos mais problemáticos refere-se a uma leitura que poderíamos classificar como idílica acerca das relações raciais brasileiras, especialmente na sua análise do período colonial, mas que, ao contrário do que uma crítica mais rasa poderia apontar, não nega, em absoluto, a existência de desigualdades étnicas no Brasil. Também se mostra frágil sua especulação sobre o futuro acerca de um progressivo desaparecimento do negro, enquanto tipo "puro", em favor da constituição de uma população cada vez mais miscigenada, mais "morena" (Freyre, 2001a), tendo em vista o processo crescente de politização da categoria raça, condição sine qua non para a implementação da Lei n. ${ }^{0}$ 10.639/03, assim como das ações afirmativas no ensino superior. Porém, apesar dos limites claramente postos, não teríamos como pensar um Brasil plural, culturalmente, sem elaboração realizada pelo intelectual de Apipucos.

\section{Considerações finais}

Certamente, apesar dos avanços que tem havido no processo de implementação da Lei n. ${ }^{0}$ 10.639/03 (Gomes, Jesus, 2013), há muito que se debater e aprofundar nessa questão, considerando-se inclusive, para além dos limites culturais e sociais postos numa agenda de constituição de um conjunto de políticas públicas 
antirracistas no Brasil, os limites estruturais existentes na realidade educacional brasileira, especialmente no que diz respeito à formação docente e às condições de trabalho impostas.

Há em curso o processo de constituição de uma nova geração pedagógica entendida aqui como o período no qual cada professor realizou seu último curso de formação docente, considerando que foi exposto ao debate pedagógico e literatura característicos de seu tempo (Weber, 1996) -, na qual há uma clareza sobre o papel da escola na construção de uma sociedade mais democrática e igualitária; projeto que engloba, necessariamente, as lutas antirracistas. E, para essa geração, reduzir Gilberto Freyre ao inventor do "mito da democracia racial”, rejeitando sumariamente sua contribuição inestimável para pensarmos a formulação da cultura afro-brasileira, seria um equívoco profundo.

Como pude argumentar, contrariamente a uma visão amplamente difundida, Freyre não negou as desigualdades étnicas existentes no Brasil - ainda que as amenizasse e exaltasse demasiadamente nossa capacidade de matizá-las por meio da miscigenação, especialmente quando em um movimento comparativo -; muito pelo contrário, não apenas as afirmou como ainda tece considerações relevantes para pensarmos a relação entre a educação e o combate ao racismo, dado que seus trabalhos indicam a ascensão progressiva do mulato e do mestiço na sociedade brasileira por meio do acesso à educação, especialmente a partir do século XIX $X^{4}$.

Também tive a oportunidade de demonstrar, ainda que brevemente, que, apesar das polêmicas envolvendo sua obra, sua leitura em torno da presença e relevância do negro na constituição da sociedade e cultura brasileiras converge com o que é proposto pela Lei n. ${ }^{0} 10.69 / 03$. Se nesse campo ainda há muito que avançar, no processo de implementação desse dispositivo legal, certamente uma apreensão cuidadosa dos trabalhos de Gilberto Freyre é uma condição indispensável para tanto.

\footnotetext{
4. Neste trabalho, não estou assumindo como verdades históricas inquestionáveis os dados trazidos por Freyre em sua obra, pois minha preocupação é apresentar como estas questões se apresentam no desenho interno do conjunto de seus trabalhos, e não confrontá-las com a perspectiva de outros autores, tendo em vista os limites deste artigo. É importante lembrar que Sobrados \& Mucambos foi publicado originalmente em 1936 e contou com uma segunda edição em 1949, que foi ampliada em número de capítulos, ganhou um novo e longo prefácio e inúmeras notas de rodapé, que cumprem a função justamente de debater com seus críticos e apresentar dados de outros pesquisadores brasileiros e estrangeiros, visando com isso reforçar seus argumentos e refutar os questionamentos que surgiram. Em tempo, é importante lembrar que, em termos metodológicos, Freyre entendia a intuição como algo indispensável para a construção do conhecimento sociológico, de modo que seus argumentos também encontram aí boa parte de seu sustentáculo e não apenas nas fontes históricas.
} 


\section{Referências}

AMADO, Gilberto et al. Gilberto Freyre - sua ciência, sua filosofia, sua arte: ensaios sobre o autor de "Casa-Grande \& Senzala" e sua influência na moderna cultura do Brasil, comemorativos do $25^{\circ}$ aniversário da publicação deste seu livro. Rio de Janeiro: José Olympio, 1962.

ANDRADE, Manuel Correia de. Gilberto Freyre e os grandes desafios do século XX. Petrópolis, RJ: Vozes, 2002.

BASTOS, Elide Rugai. As criaturas de prometeu: Gilberto Freyre e a formação da sociedade brasileira. São Paulo: Global, 2006.

BRASIL. Lei no 10.639 de 9 de janeiro de 2003. Altera a Lei no 9.394, de 20 de dezembro de 1996, que estabelece as diretrizes e bases da educação nacional, para incluir no currículo oficial da rede de ensino a obrigatoriedade da temática "História e Cultura Afro-Brasileira", e dá outras providências. Diário Oficial da União, Brasília, 10 de janeiro 2003.

BRASIL. Orientações e ações para educação das relações etnico-raciais. Brasília: SECAD, 2006.

BRASIL. Parâmetros curriculares nacionais diretrizes curriculares nacionais para a educação das relações etnico-raciais e para o ensino de história e cultura afrobrasileira e africana s. Brasília: MEC/SEF, 1997.

BRASIL. Parecer CNE/CP n. 003/2004. Diretrizes curriculares nacionais para a educação das relações étnico-raciais e para o ensino de história e cultura afrobrasileira e africana. Diário Oficial da União, Brasília, 15 de maio 2004.

BURKE, Peter. Gilberto Freyre e a nova história. Tempo soc., 1997, v.9, n.2, pp.1-12. CARDOSO, Fernando Henrique. Pensadores que inventaram o Brasil. São Paulo: Companhia das Letras, 2013.

CONSORTE, Josildeth Gomes. Culturalismo e educação nos anos 50: 0 desafio da diversidade. Cad. CEDES, 1997, v.18, n. 43, pp.26-37.

LARRETA, Enrique Rodríguez; GIUCCI, Guilhermo. Gilberto Freyre: uma biografia cultural. Rio de Janeiro: Civilização Brasileira, 2007.

LEHMANN, David. Gilberto Freyre: a reavaliação prossegue. Horiz. antropol., 2008, v.14, n. 29, pp.369-385.

LEVI-STRAUSS, Claude. O Cru e o cozido. São Paulo: Cosac Naify, 2010.

FREYRE, Gilberto. Açúcar: uma sociologia do doce, com receitas de bolos e doces do nordeste do Brasil. São Paulo: Global, 2007.

Além do apenas moderno: sugestões em torno de possíveis futuros do homem, em geral, e do homem brasileiro, em particular. São Paulo: Global, 2001a. - Casa grande \& senzala: formação da família brasileira sob o regime da economina patriarcal. São Paulo: Global, 2005. 
. Como e porque sou e não sou sociólogo. Brasília: Editora Universidade de Brasília, 1968.

Interpretações do Brasil: aspectos da formação social brasileira como processo de amalgamento de raças e culturas. São Paulo: Companhia das Letras, $2001 \mathrm{~b}$.

Novo mundo nos trópicos. São Paulo: Global, 2011.

O anarquista de apipucos. [15 de março, 1980]. Recife: Parceiros do Tempo. Entrevista concedida a Lêda Rivas. Disponível em: http://bvgf.fgf.org.br/ portugues/vida/entrevistas/anarquista.html: Acesso em: 16 de abr. 2014.

. Ordem \& progresso: processo de desintegração das sociedades patriarcal e semipatriarcal no Brasil no Brasil sob o regime de trabalho livre: aspectos de um quase meio-século de transição do trabalho escravo para o trabalho livre; e da monarquia para a república. São Paulo: Global, 2004.

. Palavras às professoras rurais do nordeste. Recife: Secretaria de Educação e Cultura, 1957.

. Palavras repatriadas. Brasília: Editora da Universidade de Brasília, 2003. - Problemas brasileiros de antropologia. Rio de Janeiro: Livraria José Olympio Editora, 1973.

Sobrados \& mucambos: decadência do patriarcado e desenvolvimento do urbano. Global: São Paulo, 2006.

- Vida social no Brasil nos meados do século XIX. São Paulo: Global, 2008.

GOHN, Maria da Glória. Teorias dos movimentos sociais: paradigmas clássicos e contemporâneos. São Paulo: Edições Loyola, 2010.

GOMES, Nilma Lino; JESUS, Rodrigo E.. As práticas pedagógicas de trabalho com relações étnico-raciais na escola na perspectiva de Lei 10.639/2003: desafios para a política educacional e indagações para a pesquisa. Educar em Revista, s/v., n. 47, pp. 19-33, 2013.

Movimento negro e educação: ressignificando e politizando a raça. Educação \& Sociedade, v. 33, n. 120, pp. 727-744, 2012.

GUSMÃO, Neusa Mendes de. Africanidades e Brasilidades: desafio da formação docente. REALIS - Revista de Estudos Antiutilitaristas e poscoloniais, v. 2, n. 2, pp. 93-108, 2012.

MEUCCI, Simone. Gilberto Freyre e a sociologia no Brasil: da sistematização à constituição do campo científico. 2006. Tese (Doutorado em Sociologia) - linstituto do Filosofia e Ciências Humanas, Universidade Estadual de Campinas, Campinas, 2006.

Gilberto Freyre e o tema da educação: o Centro Regional de Pesquisas Educacionais do Recife. In: 360 Encontro Anual da ANPOCS, 2012, Águas de Lindóia. Disponível em: <http://portal.anpocs.org/portal/index.php?option=com_ 
docman\&task=do c_view\&gid=8160\& Itemid=217>. Acesso em: 12 abr. 2014. MOTTA, Roberto. Paradigmas de interpretação das relações raciais no Brasil. Estudos Afro-Asiáticos, s/v., n. 38, pp. 113-134, 2000.

. Reação a Max Weber no pensamento brasileiro: 0 caso de Gilberto Freyre. Estudos de Sociologia, v. 13, n. 1, pp. 185-206, 2008.

MOTTA, Roberto; FERNANDES, Marcionilia. Gilberto Freyre: região, tradição, trópico e outras aproximações. Rio de Janeiro: Instituto Miguel de Cervantes, 2013. PALLARES-BURKE, Maria Lúcia. Gilberto Freyre - um vitoriano nos trópicos. São Paulo: Editora UNESP, 2005.

PALLARES-BURKE, Maria Lúcia; BURKE, Peter. Repensando os trópicos: um retrato intelectual de Gilberto Freyre. São Paulo: Editora UNESP, 2009.

RODRIGUES, Tatiane Cosentino; ABRAMOWICZ, Anete. 0 debate contemporâneo sobre a diversidade e a diferença nas políticas e pesquisas em educação. Educ. Pesqui., 2013, v.39, n.1, pp.15-30.

SCHWARCZ, Lilia Mortiz. 0 espetáculo das raças: cientistas, instituições e questão racial no Brasil do século XIX. São Paulo: Companhia das Letras, 1993.

SOUZA, Jessé. Gilberto Freyre e a singularidade cultural brasileira. Tempo Social. v. 12, n. 1, 2000.

WEBER, Silke. 0 Professor e o papel da educação na sociedade. Papirus: Campinas, 1996.

Recebido em junho de 2014

Aprovado novembro de 2014

Amurabi Oliveira é doutor em sociologia pela Universidade Federal de Pernambuco (UFPE). Atualmente é professor da Universidade Federal de Santa Catarina (UFSC), atuante em seu programa de pós-graduação em sociologia política e colaborador do programa de pós-graduação em educação da Universidade Federal de Alagoas (UFAL). E-mail: amurabi_csahotmail.com 